\title{
Bispyrenylalkane Chemosensor for the Naked-eye Detection of Nitro-explosives
}

\author{
I.S. Kovalev ${ }^{a}$, L.K. Sadieva ${ }^{\text {a,b, }}{ }^{*}$, O.S. Taniya ${ }^{a, b}$, V.M. Yurk ${ }^{a}$, A.S. Minin ${ }^{a, b}$,

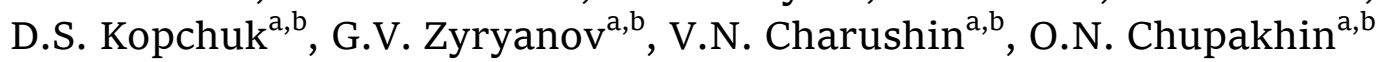 \\ a: Ural Federal University, 19 Mira St., Yekaterinburg 620002, Russia \\ b: Postovsky Institute of Organic Synthesis, Ural Branch of the Russian Academy of Sciences, \\ 22 S. Kovalevskoi / 20 Akademicheskaya St., Yekaterinburg 620219, Russia \\ * Corresponding author: leilasad@yandex.ru
}

This short communication (letter) belongs to the regular issue.

(C) 2021, The Authors. This article is published in open access form under the terms and conditions of the Creative Commons Attribution (CC BY) license (http://creativecommons.org/licenses/by/4.0/).

\section{Abstract}

Pyrene-based compounds have a great potential as fluorescent chemosensors for various analytes including common nitroexplosives, such as 2,4,6-trinitrotoluene (TNT). Compounds having two pyrene units in one molecule, such as bispyrenylalkanes, are able to form stable, bright emissive in a visual wavelength region excimers both in non-polar and polar environments. In this work we wish to report that in non-polar solvents the excimer has poor chemosensing properties while in aqueous solutions it provides significant "turn-off" fluorescence response to TNT in the subnanomolar concentrations.

\section{Keywords}

detection of explosives in aqueous media chemical sensors pyrene-based fluorophores fluorescence quenching

Received: 15.04.2021

Revised: 20.05.2021

Accepted: 20.05.2021

Available online: 20.05 .2021

\section{Introduction}

Due to an increased terrorism threats, the remote detection of TNT and DNT as main components of explosive blends [1] has become an actual task. Visual detection of explosives [2-5] is one of the oldest analytical techniques offering vast possibilities for the on-site, real-time analysis with a very fast response time. Among the visual methods, fluorescence [6-9] "turn-off" [10-15] detection is the most convenient due to high sensitivity and fast response time; in the last two decades, various fluorescent sensors for many analytes, including (nitro)explosives, have been reported. Among many fluorescent chemosensors [16], those based on polycyclic aromatic hydrocarbons (PAHbased) have gained wide attention owing to their unique fluorescent properties, such as long-wavelength excimer emission [17] either in a solution [18] or in a solid state. And pyrene-based chemosensors can be ideal candidates to use in PAH-based chemosensors because of the wellknown pyrene intense emission with long lifetime values [19-28], tendency to form excimers [29] and high sensitivity to electron-deficient molecules (e.g., nitroaromatics) $[30,31]$.

In this manuscript we wish to report our study of the ability of the simple bispyrenylalkane chemosensor to ef- fectively detect a common nitro-explosive, such as 2,4,6-trinitrotoluene (TNT).

\section{Experimental}

Starting materials are commercially available. UV-Vis absorption spectra were measured on the spectrophotometer Shimadzu UV-16oo (Japan). Emission and excitation spectra were measured on the Horiba FluoroMax-4 (USA). The emission spectra were normalized automatically using the "Normalize columns" option in the OriginPro 2015 software (64-bit) b9.2.196. Fluorescence titration experiments were carried out by using the Horiba-Fluoromax-4 spectrofluorometer (USA). Photos were taken with the Canon D30oo Kit camera.

\section{Results and Discussion}

Chemosensor 1 was prepared as reported earlier [32,33] by using the condensation reaction between the 1-pyrenecarboxaldehyde and acetone with the following reduction of the obtained condensation product (Fig. 1).

Next, the photophysical properties of compound $\mathbf{1}$ in the absence and in the presence of TNT were studied. Previously, the intensive excimer emission of $10^{-5} \mathrm{M}$ solutions of compound $\mathbf{1}$ in methylcyclohexane was reported [32]. 


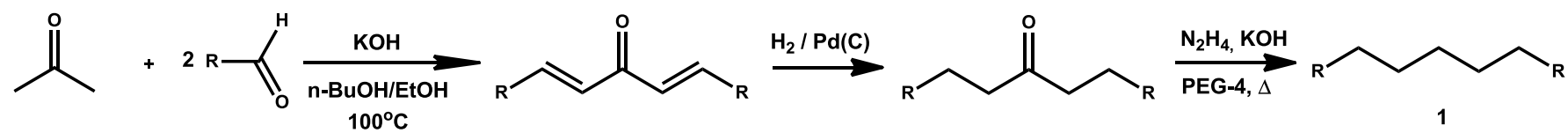

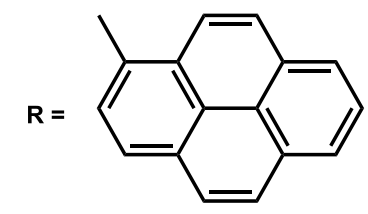

Fig. 1 Synthetic scheme for sensor 1

However, in our experiments only a feeble response through the excimer fluorescence quenching with poor linearity in the Stern-Volmer plot was observed in cyclohexane.

Based on the earlier reports [34,35], we suggested that the polarity of a solvent can be the driving force for the geometry changes in the molecule of $\mathbf{1}$, which are highly soluble in non-polar solvents. In polar solvent media, this lipophilic molecule could act as a surfactant and the hydrophobic interactions would make molecule $\mathbf{1}$ to bend over the pentane linker. In this case, the proximity effect between two pyrene moieties will result in excimer emission, while the monomeric emission of $\mathbf{1}$ will be suppressed. In addition, the lipophilic nature of the interior of the cavity formed by molecule 1 would provide a driving force for the transport of TNT molecules from the polar solvent media inside the non-polar micellar chemosensor to cause the dramatic excimer fluorescence quenching.
To prove that, the photophysical studies of compounds $1\left(10^{-6} \mathrm{M}\right)$ in different solvent systems were carried out. The selected solvents were arranged in the order of their increasing polarity: cyclohexane, THF (tetrahydrofuran), DMSO (dimethyl sulfoxide), and various solutions of DMSO in water. As it was expected, upon the increasing the polarity of solvents, a gradual decrease in the absolute intensity of the monomer emission was observed (Fig. 2), along with an increase in the intensity of the excimer emission. The highest excimer emission was observed for the $50 \%$ aqueous solution of DMSO, and this solvent was selected for our experiments.

The visual detection experiments were carried out for the solution of sensor $\mathbf{1}$ by using common borosilicate glass vials $(10 \mathrm{~mL})$, and the picture is presented below (Fig. 3). Thus, depending on the concentration of TNT $\left(10^{-4} \mathrm{M}\right.$ solution of in acetonitrile) added to the $10^{-6} \mathrm{M}$ solution of sensor 1 in DMSO/ $\mathrm{H}_{2} \mathrm{O}$ (1:1), different degree of fluorescence quenching was observed $\left(\lambda_{\mathrm{ex}}=365 \mathrm{~nm}\right)$.

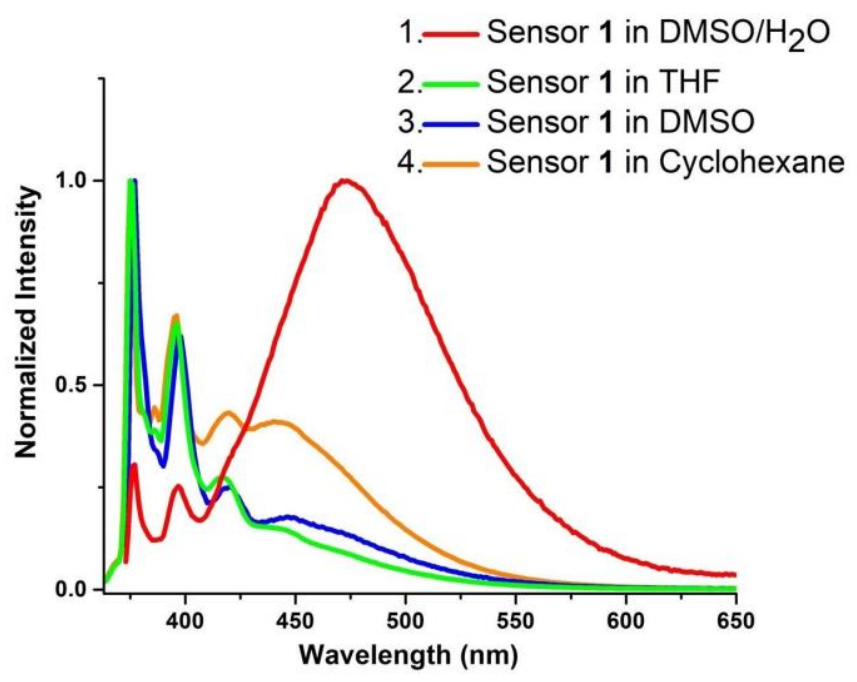

Fig. 2 Emission spectra (left) and normalized emission spectra (right) of sensor $\mathbf{1}\left(10^{-6} \mathrm{M}\right)$ in the solvents of different polarity

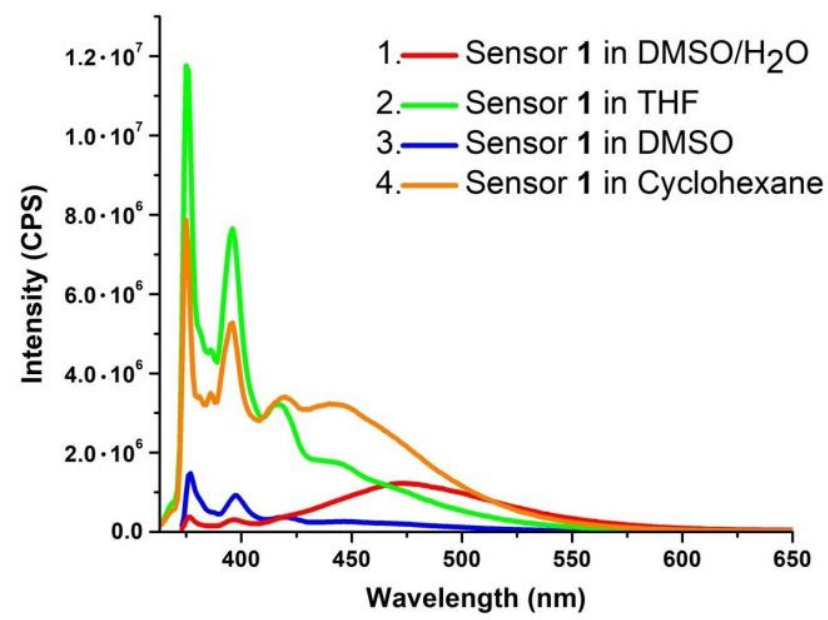

1. Sensor 1 in $\mathrm{DMSO} / \mathrm{H}_{2} \mathrm{O}$

3.- Sensor 1 in DMSO

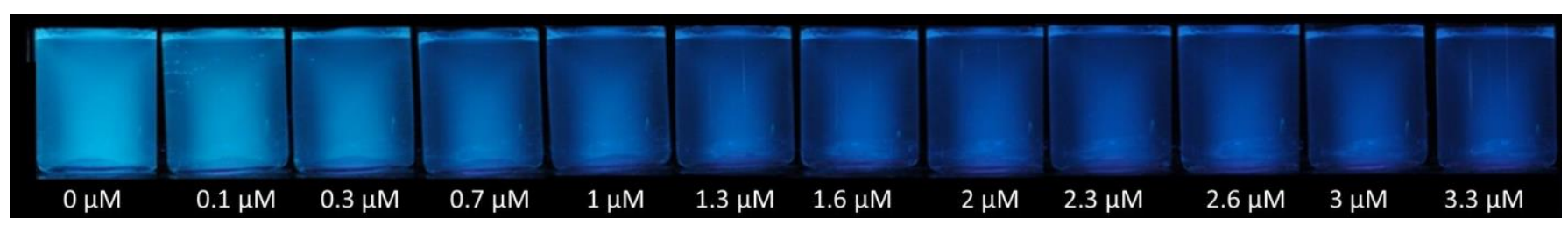

Fig. 3 The visual detection experiment for chemosensor 1 in DMSO/ $\mathrm{H}_{2} \mathrm{O}(1: 1)$ : pictures of sensor $\mathbf{1}$ under UV light $(\lambda=365 \mathrm{~nm})$ after stepwise addition of nitro explosive (TNT) 
Next, the fluorescence quenching titration was carried out. The fluorescence response of the chemosensor towards the nitro-analyte was quantitatively calculated using the Stern-Volmer static quenching model according to Eq. (1):

$$
\frac{I_{0}}{I}=1+K_{\mathrm{SV}}[\mathrm{Q}] \text {. }
$$

The calculated Stern-Volmer constant value for TNT was determined to be as high as $K_{\mathrm{sv}}=4.67 \cdot 10^{5} \mathrm{M}^{-1}$ for the static quenching model (Fig. 4). At low concentration of TNT quencher the close to linear behavior of Stern-Volmer plots was observed, which suggests the prevalence of only one quenching mechanism, such as static quenching.

The calculated limit of detection (LOD) of $143 \mu \mathrm{g} / \mathrm{L}$ (136 ppb) for the sensor 1 was estimated as reported earlier [36].

\section{Conclusions}

In summary, we described a tunable bispyrenylalkane chemosensor, which provides a simple, fast and convenient way for the detection of common nitroaromatic explosive $(2,4,6-\mathrm{TNT})$ in aqueous solutions. Its sensory response is visible enough to be detected even by the naked eye. The value of the Stern-Volmer constant of the fluorescence quenching for 2,4,6-trinitrotoluene was found to be high and equal to $4 \cdot 67 \cdot 10^{5} \mathrm{M}^{-1}$.

\section{Acknowledgements}

This work was supported by the Russian Foundation for Basic Research (Project № 19-33-90155).

\section{References}

1. Yinon J, Zitrin S. The Analysis of Explosives. Elsevier; 1981. $322 \mathrm{p}$.

2. Kangas MJ, Burks RM, Atwater J, Lukowicz RM, Williams P, Holmes AE. Colorimetric Sensor Arrays for the Detection and Identification of Chemical Weapons and Explosives. Crit Rev Anal Chem. 2017;47(2):138-53. doi:10.1080/10408347.2016.1233805

3. Jenkins TF, Walsh ME. Development of field screening methods for TNT, 2,4-DNT and RDX in soil. Talanta. 1992;39(4):419-28. doi:10.1016/0039-9140(92)80158-A

4. Li Z, Askim JR, Suslick KS. The Optoelectronic Nose: Colorimetric and Fluorometric Sensor Arrays. Chem Rev. 2019;119(1):231-92. doi:10.1021/acs.chemrev.8boo226

5. Wen P, Amin M, Herzog WD, Kunz RR. Key challenges and prospects for optical standoff trace detection of explosives. TrAC - Trends Anal Chem. 2018;100:136-44. doi:10.1016/j.trac.2017.12.014

6. Sun X, Lei Y. Fluorescent carbon dots and their sensing applications. TrAC - Trends Anal Chem. 2017;89:163-80. doi:10.1016/j.trac.2017.02.001

7. Sun X, Wang Y, Lei Y. Fluorescence based explosive detection: From mechanisms to sensory materials. Chem Soc Rev. 2015 Nov 21;44(22):8019-61. doi:10.1039/c5cso0496a

8. Zyryanov GV, Kopchuk DS, Kovalev IS, Nosova EV, Rusinov VL, Chupakhin ON. Chemosensors for detection of nitroaromatic compounds (explosives).

Russ Chem Rev. 2014;83(9):783-819. doi:10.1070/RC2014v083nogABEH004467

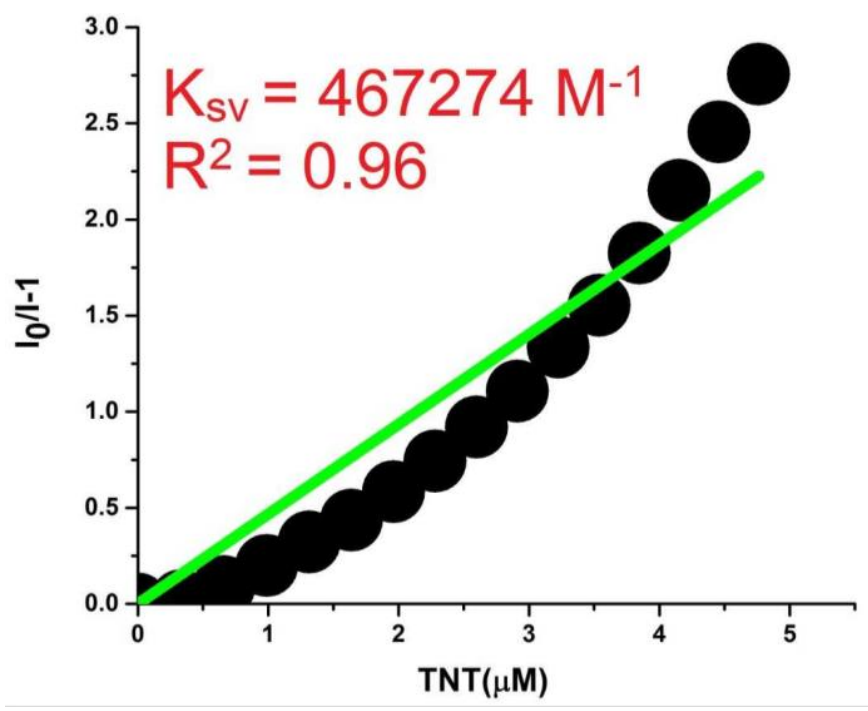

Fig. 4 Stern-Volmer plot of emission quenching for sensors 1: points - experimental data, line - linear fit

9. Salinas Y, Martínez-Máñez R, Marcos MD, Sancenón F, Costero AM, Parra M, Gil S. Optical chemosensors and reagents to detect explosives. Chem Soc Rev. 2012;41(3):126196. doi: $10.1039 / \mathrm{c} 1 \mathrm{cs} 15173 \mathrm{~h}$

10. Zyryanov GV, Palacios MA, Anzenbacher P. Simple MoleculeBased Fluorescent Sensors for Vapor Detection of TNT. Org Lett. 2008;10(17):3681-4. doi:10.1021/01801030u

11. Beyazkilic P, Yildirim A, Bayindir M. Formation of Pyrene Excimers in Mesoporous Ormosil Thin Films for Visual Detection of Nitro-explosives. ACS Appl Mater Interfaces. 2014;6(7):4997-5004. doi:10.1021/am406035v

12. Xiao FN, Wang K, Wang FB, Xia XH. Highly Stable and Luminescent Layered Hybrid Materials for Sensitive Detection of TNT Explosives. Anal Chem. 2015;87(8):4530-7. doi:10.1021/acs.analchem.5boo630

13. Demirel GB, Daglar B, Bayindir M. Extremely fast and highly selective detection of nitroaromatic explosive vapours using fluorescent polymer thin films. Chem Commun. 2013;49(55):6140-2. doi:10.1039/c3cc43202e

14. Andrew TL, Swager TM. A Fluorescence Turn-On Mechanism to Detect High Explosives RDX and PETN. J Am Chem Soc. 2007;129(23):7254-5. doi:10.1021/jao71911C

15. Mosca L, Karimi Behzad S, Anzenbacher P. Small-Molecule Turn-On Fluorescent Probes for RDX. J Am Chem Soc. 2015;137(25):7967-9. doi:10.1021/jacs.5bo4643

16. Wu D, Sedgwick AC, Gunnlaugsson T, Akkaya EU, Yoon J, James TD. Fluorescent chemosensors: The past, present and future. Chem Soc Rev. 2017;46(23):7105-23. doi:10.1039/c7csoo240h

17. Ohno K, Satoh H, Iwamoto T. Quantum chemical exploration of dimeric forms of polycyclic aromatic hydrocarbons, naphthalene, perylene, and coronene. Chem Phys Lett. 2019;716:147-54. doi:10.1016/J.CPLETT.2018.12.034

18. Marsh AV, Cheetham NJ, Little M, Dyson M, White AJP, Beavis P, Warriner CN, Swain AC, Stavrinou PN, Heeney M. Carborane-Induced Excimer Emission of Severely Twisted Bis- $o$-Carboranyl Chrysene. Angew Chemie Int Ed. 2018;57(33):10640-5. doi:10.1002/anie.201805967

19. Šoustek P, Michl M, Almonasy N, Machalický O, Dvořák M, Lyčka A. The synthesis and fluorescence of N-substituted 1- and 2-aminopyrenes. Dye Pigment. 2008;78(2):139-47. doi:10.1016/j.dyepig.2007.11.003

20. Suzuki Y, Morozumi T, Nakamura H, Shimomura M, Hayashita T, Bartsh RA. New fluorimetric alkali and alkaline earth metal cation sensors based on noncyclic crown ethers by means of intramolecular excimer formation of pyrene. J Phys Chem B. 1998;102(40):7910-7. doi:10.1021/jpg81567t 
21. Hrdlovič P, Horinová L, Chmela Š. Spectral properties of ionic derivatives of pyrene and their aggregates with anionic surfactant and polyelectrolyte. Can J Chem. 1995;73(11):1948-54. doi:10.1139/v95-240

22. Daems D, Van den Zegel M, Boens N, De Schryver FC. Fluorescence decay of pyrene in small and large unilamellar L, $\alpha$-Dipalmitoylphosphatidylcholine vesicles above and below the phase transition temperature. Eur Biophys J. 1985;12(2):97-105. doi:10.1007/BFo0260432

23. Kim JJ, Beardslee RA, Phillips DT, Offen HW. Fluorescence lifetimes of pyrene monomer and excimer at high pressures. J Chem Phys. 1969;51:2761-2. doi:10.1063/1.1672406

24. Ruiu A, Vonlanthen M, Rojas-Montoya SM, González-Méndez I, Rivera E. Unusual fluorescence behavior of pyrene-amine containing dendrimers. Molecules. 2019;24(22). doi: $10.3390 /$ molecules 24224083

25. Lin TI. Excimer fluorescence of pyrene-tropomyosin adducts. Biophys Chem. 1982;15(4):277-88. doi:10.1016/0301-4622(82)80011-2

26. Wang X, Liu L, Zhu S, Peng J, Li L. Preparation of exciplexbased fluorescent organic nanoparticles and their application in cell imaging. RSC Adv. 2017;7(65):40842-8. doi:10.1039/c7rao8142a

27. Kanagalingam S, Spartalis J, Cao TM, Duhamel J. Scaling relations related to the kinetics of excimer formation between pyrene groups attached onto poly(N,N-dimethylacrylamide)s. Macromolecules. 2002;35(22):8571-7. doi: $10.1021 / \mathrm{maO} 20784 \mathrm{~W}$

28. Bertolotti SG, Previtali CM. Fluorescence of pyrene derivatives in the presence of poly(methallyl sulfonate-vinyl acetate) copolymers. effect of charge density. J Macromol Sci Part A. 1994;31(4):439-49. doi:10.1080/10601329409351530
29. Förster T, Kasper K. Ein Konzentrationsumschlag der Fluoreszenz des Pyrens. Zeitschrift für Elektrochemie, Berichte der Bunsengesellschaft für Phys Chemie. 1955;59(10):9768o. German. doi:10.1524/zpch.1954.1.5 6.275

30. Rehm D, Weller A. Kinetics of Fluorescence Quenching by Electron and H-Atom Transfer. Isr J Chem. 1970;8(2):259-71. doi:10.1002/ijch.197000029

31. Goodpaster JV, McGuffin VL. Fluorescence quenching as an indirect detection method for nitrated explosives. Anal Chem. 2001;73(9):2004-11. doi:10.1021/ac001347n

32. Zachariasse K, Kühnle W. Intramolecular Excimers with $\alpha, \omega$-Diarylalkanes. Zeitschrift für Phys Chemie. 1976;101(1-6):267-76. doi:10.1524/zpch.1976.101.1-6.267

33. Ikeda T, Lee B, Tazuke S, Takenaka A. Time-resolved observation of excitation hopping between two anthryl moieties attached to both ends of alkanes: simulation based on conformational analysis. J Am Chem Soc. 1990;112(12):4650-6. doi:10.1021/jaoo168a004

34. Zhang $\mathrm{P}$, Zhang L, Wang $\mathrm{H}$, Zhang DW, Li ZT. Helical folding of an arylamide polymer in water and organic solvents of varying polarity. Polym Chem. 2015;6(15):2955-61. doi:10.1039/C5PYoo096C

35. Ikai T, Shimizu S, Awata S, Kudo T, Yamada T, Maeda K, Kanoh S. Synthesis and chiroptical properties of a $\pi$-conjugated polymer containing glucose-linked biphenyl units in the main chain capable of folding into a helical conformation. Polym Chem. 2016;7(48):7522-9. doi:10.1039/C6PY01759B

36. Shrivastava A, Gupta V. Methods for the determination of limit of detection and limit of quantitation of the analytical methods. Chronicles Young Sci. 2011;2(1):21. doi:10.4103/2229-5186.79345 